\title{
Susceptibility of Selected Multi-Drug Resistant Clinical Isolates to Different Leaf Extracts of Senna alata
}

\author{
Ibikunle I. ANIBIJUWON*, Ifeoluwa Deborah GBALA, \\ Bright I. NNADOZIE, Olubukola O. IFAYEFUNMI \\ University of Ilorin, Department of Microbiology, Public Health Laboratory Unit, P.M.B. 1515, Ilorin, \\ Nigeria; kunledoexploit@gmail.com (*corresponding author)
}

\begin{abstract}
The present study evaluated the antibacterial effects of the methanolic, ethanolic and aqueous extracts of Senna alata leaves. The extracts were tested using agar well diffusion method against selected clinical isolates: Salmonella typhi, Escherichia coli, Pseudomonas aeruginosa, Staphylococcus aureus and Klebsiella pneumoniae. Antibiogram profile of the isolates deduced by disc diffusion method confirmed that the methanolic extract inhibited the growth of all tested organisms except for Klebsiella pneumoniae, which also showed no sensitivity to the ethanolic extract. There was no inhibition observed for the aqueous extract against all the tested organisms, indicating that the methanolic extract of the plant was more potent than the aqueous extract. Inhibitory activities were observed for gentamicin, ofloxacin and erythromycin against Staphylococcus aureus and Escherichia coli. No inhibitory activity was observed in all the antibiotics against Pseudomonas aeruginosa. In Klebsiella pneumoniae, inhibition was only observed in ofloxacin. The activity of both the methanolic and ethanolic extract of Senna alata was optimal under different concentrations, but gradually diminished as the concentration was adjusted. The activity of the plant extracts against the selected bacteria is an indication of the presence of broad spectrum bioactive compounds which could be explored in the therapy of bacterial infections.
\end{abstract}

Keywords: antibiotic resistance; minimum inhibitory concentration; minimum bactericidal concentration

\section{Introduction}

Medicinal plants have been used for centuries as remedies for infectious diseases because of the presence of components with therapeutic value. Infectious disease accounts for one half of all deaths in the tropical countries irrespective of efforts made in controlling the incidence of an epidemic (Decock et al., 2013). It is therefore necessary that the search for plants as antibiotic or therapeutic potential to be a continue process. Several findings have accumulated and proven the potentials of medicinal plants used in traditional medicine in the treatment of several human diseases; these studies have identified compounds within herbal plants that are effective as antibiotics (Mahmood and Amey, 2007; Ekor, 2013).

Antimicrobial resistance in bacteria has become prominent so much that a bacterium may exhibit non sensitivity to a wide variety of several classes of antibiotics used in a study. These phenomena, coupled with the propensity of spread of resistance genes among bacteria, increase the rate of fatality and mortality of bacterial infections. It is therefore pertinent to investigate newer drugs or sources with potential of lower resistance evolution. Most drugs presently prescribed by physicians are either directly isolated from plants or are artificially modified versions of natural products (Katiyar et al., 2012) and in-spite of vast improved health care delivery in developed nations of the world, like the United States of America and Europe, these countries are now turning back to traditional phytomedicine in order to prevent or treat many ailments (Saikat et al., 2016). The demands for traditional herbal medicines is increasing globally, because it is cheap, safe and able to compete with most commercial antibiotics that bacterial pathogens are now even becoming resistant to. In Nigeria, various plant parts are used in treatment of different ailments with remarkable success. Among these enormous numbers of medicinal plants are members of the genus Senna.

Senna alata is an important medicinal tree, as well as an ornamental flowering plant, in the subfamily Caesalpinioideae. It is one of the most important species of the genus Senna which is rich in anthraquinones and polyphenols (Afrin, 2015). It is native to Mexico, but can be found in diverse habitats. Senna alata is often called the 
ringworm bush because of its very effective fungicidal properties, for treating ringworm and some other fungal infections of the skin (Afrin, 2015), while the root decoction is taken in Nigerian and Guinea Bissau to regulate menstrual flow. Decoction with rock salt and other dry medicinal plants is taken in Nigeria thrice weekly on an empty stomach for effective treatment of chronic gonorrhea. Based on this background, the hereby study was designed to screen fractions of Senna alata leaf extracts for antibacterial activity against selected multi-drug resistant pathogenic bacteria of clinical origin and in the process, also determining the phytochemicals responsible for the antimicrobial activity. The assay was carried out using the agar well diffusion method and the antibacterial activity of the leaf extracts was compared with the effects of the conventional antibiotics.

\section{Materials and Methods}

\section{Collection andidentification of plantmaterial}

Fresh leaves of Senna alata were collected at nonspecific locations within Ilorin, Kwara State Nigeria. It was identified and authenticated at the Herbarium Unit of the Department of Plant Biology, University of Ilorin, Kwara State, Nigeria. All other laboratory works were carried out at the Department of Microbiology Laboratory Ilorin.

\section{Collection and maintenance of test organisms}

The pure cultures of clinical isolates used in the study Esherichia coli, Salmonella typhi, Staphylococcus aureus, Pseudomonas aeruginosa and Klebsiella pneumoniae were all obtained from Wesley Guild Hospital, Ilesha, Osun State. These isolates were thereafter tested biochemically to reaffirm their identity before storing in a working refrigerator at $4{ }^{\circ} \mathrm{C}$ as stock culture. Subcultures of the refrigerated stocks were carried out at every 2 weeks' interval to maintain the viability of the test organisms. It was also ensured that only 18 hours old cultures of the test organisms were used for the antimicrobial assay.

\section{Preparation of the leafextracts}

The fresh leaves collected were rinsed with clean tap water, air dried at room temperature and grinded into fine powder using an electronic blender (Binatone, UK). The resulting powdered plant material was sieved and stored in an air tight container prior to extraction. The solvents utilized for the extraction are ethanol (100\%), methanol (100\%) and hot water. A slightly modified method of Hubert et al. (2015) was adopted for the extraction processes. Precisely, one hundred grams $(100 \mathrm{~g})$ of the fine powered leaf was weighed using a weighing balance $(A \& D$, UK); this weighed sample was immersed in $200 \mathrm{ml}$ of each of the above mentioned solvents contained in three different carefully labeled conical flasks, to obtain three different extracts, which were accompanied by vigorous shaking for five (5) minutes and thereafter allowed to remain on the rotating shaker for 24 hours. The resulting solutions were filtered using Whatman No. 1 filter paper and the filtrates were allowed to decant, the pellets were discarded and the supernatants were concentrated in a hot water bath, then subjected to centrifugation at 2,500 revolutions per minute (rpm) for five (5) minutes for clarification; they were then sterilized by membrane filtration using Millipore filter paper and thereafter stored in sterile bottles in a working refrigerator at $4^{\circ} \mathrm{C}$.

Determination of the phytochemicals present in Senna alata leaf extracts

The phytochemical analysis of the leaf extracts was carried out for the detection of biomolecules such as: alkaloid, saponins, anthraqinones, flavonoids, tannins and cardiac glycosides using the standard qualitative procedures as described by Trease and Evans (1989).

Test for Alkaloids: $0.5 \mathrm{~g}$ of each of the extract was stirred wit $5 \mathrm{ml}$ of $1 \%$ aqueous hydrochloric acid on a steam bath. About $1 \mathrm{ml}$ of the filtrate was treated with a few drops of the Dragendroffs reagent. The formation of orange color indicated the presence of alkaloids.

Test for Saponins: $0.5 \mathrm{~g}$ of the extract was added and mixed with Fehling's solution and then $5 \%$ of sodium trioxocarbonate solution was later added. The mixture was then boiled. The pink precipitate indicated the presence of saponins.

Test for Flavonoids: $0.5 \mathrm{~g}$ of the extract and few pieces of magnesium strips was mixed with concentrated $\mathrm{HCl}$. An orange faint color of effervescence solution indicated the presence of flavonoids.

Test for Tannins: $0.5 \mathrm{~g}$ of the plant extract was stirred with $1 \mathrm{ml}$ of distilled water, filtered and ferric chloride solution or reagent was added to the filtrate. A blue black or blue green precipitate was taken as evidence for the presence of tannins.

Test for Anthraquinones: $0.5 \mathrm{~g}$ of the plant extract was boiled with $1 \mathrm{ml} 10 \%$ sulphuric acid and was filtered; $2.5 \mathrm{ml}$ of benzene was added to the filtrate and shaken. The benzene layer was separated and half its volume was added to $10 \%$ ammonia solution. The presence of a pink or redvoilet colour in the lower ammonia phase indicated the presence of anthraquinones.

\section{Determination of $p H$ of the extracts}

The $\mathrm{pH}$ of the methanolic and ethanolic extract were determined using calibrated $\mathrm{pH}$ meter (model 3510 Jenway). The electrode of the calibrated $\mathrm{pH}$ meter was immersed into the extracts to obtain the $\mathrm{pH}$ of the extracts.

\section{Antimicrobial assay of methanolic, ehanolic and aqueous solution}

Antimicrobial activity of the extracts (ethanolic, methanolic and aqueous extract) of $S$. alata was evaluated by the agar well diffusion method as described by Cheeseburough (2006). The already prepared Muller Hilton agar (Rapid Lab UK) was used in carrying out the assay by appropriately inoculating the test organisms. (Salmonella typhi, Escherichia coli, Pseudomonas aeruginosa, Staphylococcus aureus and Klebsiella pneumoniae) which were already pre-adjusted to the $0.5 \mathrm{McFarland}$ 's turbidity standard in peptone water; by dipping the sterile swab sticks into the suspension and removing excess inoculum, while pressing and rotating the swab firmly against the side of the tube. The inoculums were spread all over the surface of the media. This was achieved by dispensing $9 \mathrm{ml}$ of peptone 
28

water into a sterile McCartney bottle, 3 loopful of the inoculum was added into the water to obtain a suspension. Agar well diffusion method was employed. This was done by boring three equidistant holes on the media with the use of sterile cork borer. Appropriate quantity of the three different extracts was dispensed into the holes; i.e. each hole representing each extract (well labelled). The plates were left for 10-15 minutes to diffuse and were in turn incubated at $37^{\circ} \mathrm{C}$ for 24 hours. After incubation, the diameter of zones of inhibition were measured using a meter rule and was recorded in 'millimeter'.

\section{Effect of varying concentrations}

Varying concentrations of the extracts (methanolic and ethanolic extracts) were prepared in sterile test tubes. Six different concentrations $\left(150 \mathrm{mg} \mathrm{m}^{-1}, 100 \mathrm{mg} \mathrm{ml}^{-1}, 75 \mathrm{mg}\right.$ $\mathrm{ml}^{-1}, 50 \mathrm{mg} \mathrm{m}^{-1}, 25 \mathrm{mg} \mathrm{m}^{-1}$ and $5 \mathrm{mg} \mathrm{ml}^{-1}$ ) were prepared. The effect of these concentrations on the test organisms was checked for by inoculating the test organisms on MHA. Six equidistance holes were bore on the inoculated plates using a sterile cork-borer. Then each of the concentrations was dispensed making use of a sterile syringe, into well labelled hole. The plates were allowed to stand for 10-15 minutes to allow proper diffusion and then subsequently incubated for 24 hours at $37^{\circ} \mathrm{C}$. Visible zones of inhibitions were observed and recorded in 'millimeter'.

Determination of minimum inhibitory/bactericidal concentration $(M I C / M B C)$

The MIC/MBC of the organisms was determined following the method described by Willey et al. (2008). The organisms susceptible to the leaf extracts of $S$. alata were inoculated into sterile nutrient broth (Lab M Ltd., UK) and incubated overnight at $37^{\circ} \mathrm{C}$. Varying concentrations $(150$ $100,75,50,25$ and $\left.5 \mathrm{mg} \mathrm{m}^{-1}\right)$ of the extracts were prepared by serial dilution using Mueller Hinton broth (Rapid Lab, UK) as a diluent. Each of the diluted extract was then inoculated with $100 \mu \mathrm{L}$ of the overnight broth culture of the test organisms. Control was setup: it contained broth and the extract and another control containing broth and organism. The inoculated and control tubes were incubated at $37^{\circ} \mathrm{C}$ for $24 \mathrm{hrs}$ after which they were observed for turbidity. The lowest concentration that shows no turbidity was taken as the MIC, while the lowest concentration of the extract which showed no growth on plates after 24 hours of incubation indicates bactericidal effect and was taken as MBC

The concentrations of each extracts that showed the least and no observable growth both in the test tube and on the plate was taken as the MIC. Even so, after incubation, growth was observed on all the plates, which simply mean the concentration only has a bacteriostatic effect and could not exert a bactericidal effect on the test organisms.

\section{Antibiotics susceptibility test}

The antibiotics used for the current study (Abtek Biologicals Limited, UK) had been prepared into kit containing multiple discs impregnated with different types of antibiotics. The antibiotics used and their corresponding concentrations are as follows:

Gentamicin $(10 \mu \mathrm{g})$, Cotrimaxazole $(25 \mu \mathrm{g})$, Ofloxacin $(30 \mu \mathrm{g})$, Tetracycline $(30 \mu \mathrm{g})$, Amoxicillin $(25 \mu \mathrm{g})$,
Nitrofurantoin $(300 \mu \mathrm{g})$, Nalidixic acid $(30 \mu \mathrm{g})$ and Augmentin $(30 \mu \mathrm{g})$ for the gram-positive bacteria and Ceftazidime $(30 \mu \mathrm{g})$, Cefuroxime $(30 \mu \mathrm{g})$, Gentamicin (10 $\mu \mathrm{g})$, Ceftriaxone $(30 \mu \mathrm{g})$, Erythromycin $(5 \mu \mathrm{g})$, Cloxacillin $(5 \mu \mathrm{g})$, Ofloxacin $(5 \mu \mathrm{g})$ and Augmentin $(30 \mu \mathrm{g})$ for the gram-negative bacteria isolate.

Solidified Mueller Hinton agar (Rapid Labs, UK) plates were seeded with $100 \mu \mathrm{l}$ of the standardized organisms and were spread evenly over the total surface area of the agar using a glass spreader. The plates were left on the laboratory bench for $30 \mathrm{~min}$ to ensure that the organisms are well absorbed on the agar surface. Multiple antibiotics discs containing the aforementioned antibiotics were carefully and firmly placed on the surface of the agar using sterile forceps. The plates were then left for 1 hour to allow the antibiotics to diffuse. Afterwards, the plates were incubated at $37^{\circ} \mathrm{C}$ for $18-20$ hours. After incubation, the zones of inhibition generated by the antibiotics were measured and recorded in millimeter (mm) (CLSI, 2016). The values for each organism against the antibiotics were interpreted as sensitive, intermediate or resistant using the breakpoints interpretative criteria of Clinical and Laboratory Standard Institutes (CLSI, 2016).

\section{Determination of $p H$ of the extracts of Senna alata}

The $\mathrm{pH}$ of the extracts was determined by dipping a $\mathrm{pH}$ meter into conical flasks containing the extracts. The constant reading on the $\mathrm{pH}$ meter was taken as the $\mathrm{pH}$ of the antimicrobial substance in question (Adetitun et al., 2013).

\section{Results}

\section{Determination of $p H$ of the extracts of Senna alata}

The $\mathrm{pH}$ of the extracts was determined using a $\mathrm{pH}$ meter and the following results were obtained: aqueous extract had a $\mathrm{pH}$ of $5.42,7.8$ for methanolic extract, while ethanolic extract had a pH of 7.2 (Fig. 1).

\section{Phytochemical screening of Senna alata}

Freshly prepared extracts were subjected to preliminary phytochemical screening for various constituents present in the plant. The results (Table 1) revealed the presence of flavonoids, alkaloids, saponins, phenols, tannins, anthraquinones, carbohydrates and glycosides.

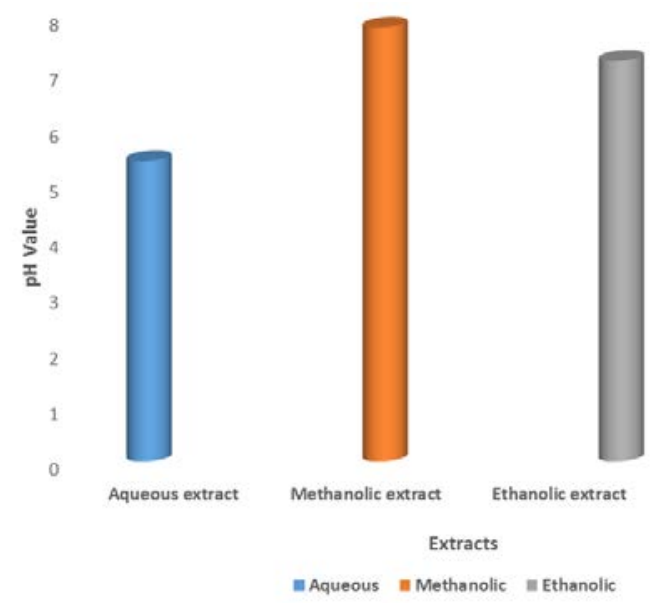

Fig. 1. The $\mathrm{pH}$ values of tested extracts of Senna alata leafs 
Table 1. Phytochemical characteristic of Senna alata

\begin{tabular}{cc}
\hline Phytochemicals & Presence of color formation \\
\hline Alkaloid & Reddish-brown coloration \\
Anthraquinones & Grey-green \\
Carbohydrate & Brick-red precipitate \\
Flavonoid & Creamy or light-yellow \\
Saponin & Formation of froth \\
Tannin & Blue-green precipitate \\
Terpenes and steroids & Reddish color interface \\
\hline
\end{tabular}

\section{Antimicrobial susceptibility test}

Susceptibility test of the extracts was carried out on the organisms to check for their antimicrobial activities making use of the stock concentration which was $200 \mathrm{mg} \mathrm{ml}^{-1}$. The methanolic extract was observed to inhibit the growth of all the test organisms except for Klebsiella pneumoniae, which also has no sensitivity to the ethanolic extract. Other test organisms were also resistant to the ethanolic extract. No inhibition was observed for the aqueous extract against all the test organisms.

The ranges of zones of inhibition observed were interpreted according to Clinical Laboratory Standard Institute (CLSI, 2016) standard. Out of all antibiotics used for both Gram positive and negative bacteria, ofloxacin, gentamicin and erythromycin showed significant inhibitory activities on two to four of the organisms. The organism that showed the most resistance to the antibiotics used was S. aureus with no visible zones of inhibition on Gentamycin and Erythromycin and significant inhibition when Ofloxacin was used with zone of inhibition of $33.5 \mathrm{~mm}$ as illustrated in Fig. 5. For the gram negative organisms, the highest inhibitory activity was observed in ofloxacin against S. typhi, K. pneumoniae and E. coli with diameter of zone of inhibition as $29.5 \mathrm{~mm}, 20.5 \mathrm{~mm}$ and $17.5 \mathrm{~mm}$ respectively. Higher inhibitory activity was observed in erythromycin against $S$. typhi and E. coli with diameter of zone of inhibition as $26.5 \mathrm{~mm}$ and $23.5 \mathrm{~mm}$. Inhibitory activity was also observed in gentamycin against $S$. typhi and E. coli and was recorded as $23 \mathrm{~mm}$ and $14 \mathrm{~mm}$ respectively. No inhibitory activity was observed in all the antibiotics against $P$. aeruginosa, in comparison with the methanolic and ethanolic extracts which have antimicrobial activity on the organism. The results showed that plant extracts are more potent than the standard antibiotics, to exert antimicrobial effect on the organism as shown on Tables 2 and 3. Both the ethanolic and methanolic extracts inhibited the growth of Escherichia coli, Staphylococcus aureus and Pseudomonas aeruginosa, though through varying degrees (Fig. 2).

There was a significantly high inhibitory activity exhibited by the extracts tested, which could be attributed to the antimicrobial properties of the plant to the presence of the bio-active secondary metabolites. In this research, the methanolic extract had higher MIC values for Staphylococcus aureus and Salmonella typhi $150 \mathrm{mg} \mathrm{m}^{-1}$ and $75 \mathrm{mg} \mathrm{ml}^{-1}$ respectively, thus indicating a lower susceptibility to the efficacy of the extract. Lower MIC value of $5 \mathrm{mg} \mathrm{ml}^{-1}$ was obtained in the methanolic extract against Pseudomonas aeruginosa, thus indicating higher activity of the extract against the organism. In Salmonella typhi, the MIC was obtained as $150 \mathrm{mg} \mathrm{ml}^{-1}$, meaning that lower concentrations other than this concentration cannot exert any antimicrobial effect on the organism (Table 3). No concentration showed inhibition against $E$. coli both in the methanolic and ethanolic extracts except for the stock concentration which was $200 \mathrm{mg} \mathrm{ml}^{-1}$; this simply means that lower concentrations cannot exert antimicrobial activity on the organism. In the ethanolic extract, lower MIC value of $5 \mathrm{mg} \mathrm{ml}^{-1}$ was observed in the organisms $(P$. aeruginosa, $S$. typhi and $S$. aureus), indicating that antimicrobial activity can be exerted by the extract even at lower concentrations as illustrated in Table 3. No inhibitory activity was observed both in the methanolic and ethanolic extracts against $K$. pneumoniae and this was speculated that the organism is resistant to the phytochemicals present in the leaf extracts.

\section{Effects of varying concentrations of the extracts}

The effect of varying concentrations of the ethanolic (Fig. 4) and methanolic (Fig. 3) extracts was assayed for, on the tested organisms. This was achieved by diluting the stock concentration to obtain the desired concentrations. The concentrations used are: $150 \mathrm{mg} \mathrm{ml}^{-1}, 100 \mathrm{mg} \mathrm{ml}^{-1}, 75$ $\mathrm{mg} \mathrm{ml}^{-1}, 50 \mathrm{mg} \mathrm{ml}^{-1}, 25 \mathrm{mg} \mathrm{m}^{-1}$ and $5 \mathrm{mg} \mathrm{ml}^{-1}$. No inhibitory activity was observed in the aqueous extract.

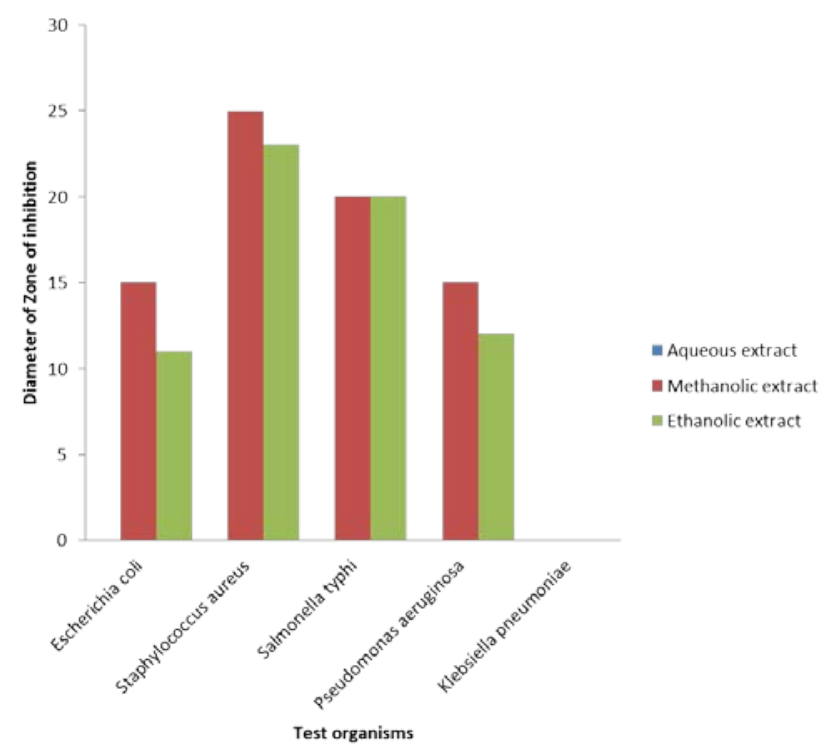

Fig. 2. Antimicrobial activity of ethanolic, methanolic and aqueous leaf extracts of Senna alata on test organisms 
30

Table 2. Minimum inhibitory and bactericidal concentrations of the ethanolic extract

\begin{tabular}{|c|c|c|c|c|c|c|c|c|}
\hline \multirow[b]{2}{*}{ Organisms } & \multirow[b]{2}{*}{150} & \multirow[b]{2}{*}{100} & \multicolumn{4}{|c|}{ Varying concentrations of the ethanolic extract (in $\mathrm{mg} \mathrm{ml}^{-1}$} & \multirow[b]{2}{*}{ MIC } & \multirow[b]{2}{*}{$\mathrm{MBC}$} \\
\hline & & & 75 & 50 & 25 & 5 & & \\
\hline $\begin{array}{c}\text { Staphylococcus } \\
\text { aureus }\end{array}$ & + & + & + & - & - & - & 5 & Nil \\
\hline $\begin{array}{c}\text { Salmonella } \\
\text { typhi }\end{array}$ & + & + & + & - & - & - & 5 & Nil \\
\hline $\begin{array}{c}\text { Pseudominas } \\
\text { aeruginosa }\end{array}$ & + & + & + & - & - & - & 5 & Nil \\
\hline
\end{tabular}

Table 3. Minimum inhibitory and bactericidal concentration of the methanolic extract

\begin{tabular}{|c|c|c|c|c|c|c|c|c|}
\hline \multirow[b]{2}{*}{ Organisms } & \multicolumn{8}{|c|}{ Varying concentrations of the methanolic extract (in $\mathrm{mg} \mathrm{m}^{-1}$ ) } \\
\hline & 150 & 100 & 75 & 50 & 25 & 5 & MIC & $\mathrm{MBC}$ \\
\hline $\begin{array}{c}\text { Staphylococcus } \\
\text { aureus }\end{array}$ & - & + & + & + & + & + & 150 & Nil \\
\hline Salmonella typhi & + & + & _ & + & + & + & 75 & Nil \\
\hline $\begin{array}{l}\text { Pseudomonas } \\
\text { aeruginosa }\end{array}$ & + & + & - & - & - & - & 5 & Nil \\
\hline
\end{tabular}

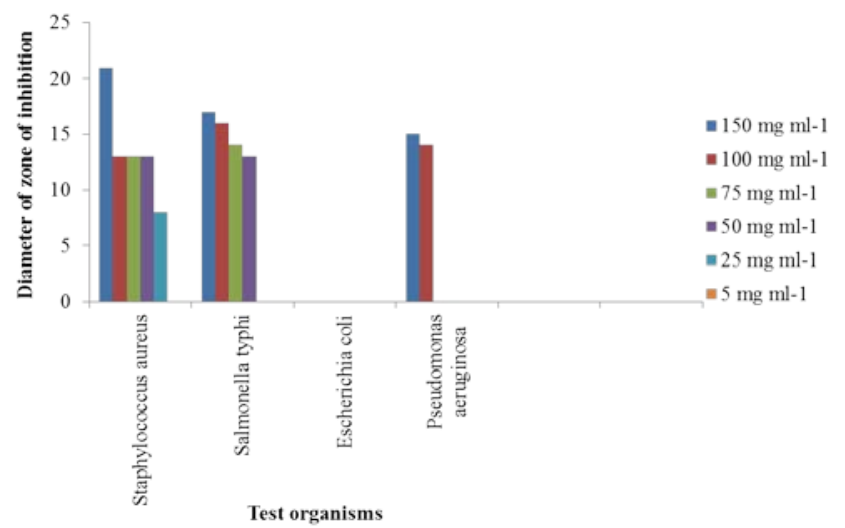

Fig. 3. The effect of varying concentrations of methanolic extract on the test organisms

\section{Minimum inbibitory and bactericidal concentration of the methanolic and ethanolic extracts}

The minimum inhibitory concentration of both the methanolic and ethanolic extracts was determined by observing the turbidity of the varying concentrations of the extracts in the test tube after incubation. The minimum inhibitory concentration of the ethanolic extract was observed as $5 \mathrm{mg} \mathrm{ml}^{-1}, 5 \mathrm{mg} / \mathrm{ml}$ and $5 \mathrm{mg} \mathrm{ml}^{-1}$ for Staphylococcus aureus, Salmonella typhi and Pseudomonas aeruginosa respectively. While for methanolic extract, the minimum inhibitory concentration was observed as $150 \mathrm{mg}$ $\mathrm{ml}^{-1}, 75 \mathrm{mg} \mathrm{ml}^{-1}$ and $5 \mathrm{mg} \mathrm{ml}^{-1}$ for the organisms respectively. No minimum bactericidal concentration was observed for both the ethanolic and methanolic extract on all the test organisms.

\section{Antibiotics susceptibility test}

The antimicrobial activity of standard antibiotics was assayed for on the test organisms. Inhibitory activity was observed on gentamicin, ofloxacin and erythromycin against

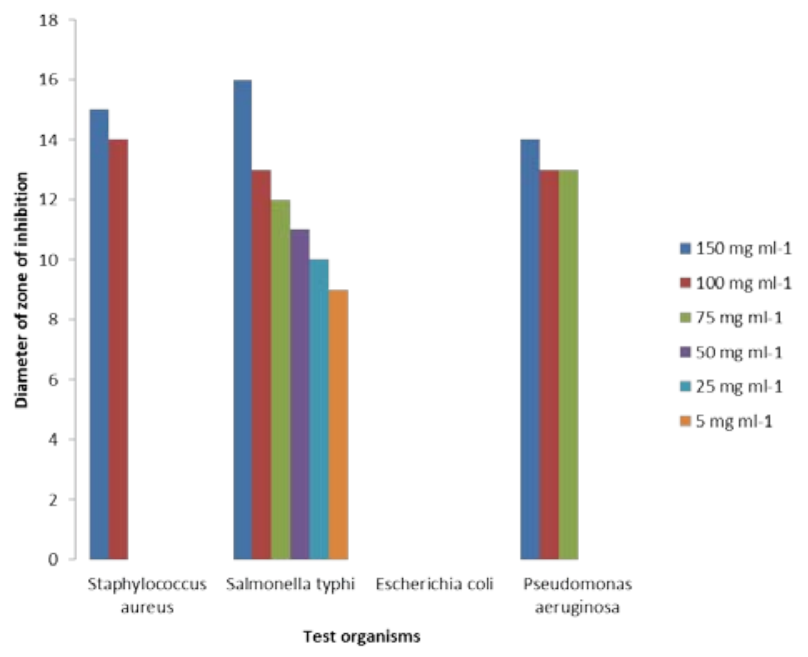

Fig. 4. The effect of varying concentration of the Ethanolic extract on the test organisms

Staphylococcus aureus and Escherichia coli. No inhibitory activity was observed in all the antibiotics against Pseudomonas aeruginosa. In Klebsiella pneumoniae, inhibition was only observed in ofloxacin (Fig. 5).

\section{Discussion}

The effective use of plants for therapy has always been attributed to the presence of pharmacologically active substances known as phytochemicals. All bacteria used in the present study were multi drug resistant. Previous researches on the phytochemical content of the leaves of Senna alata showed the presence of alkaloids, saponins, malic acid, Quinone's, tocopherol, flavonoids, polyphenols and triterpenoids (Afrin, 2015). These biologically active substances have been revered for their therapeutic efficacy. A major contribution of higher plants to both traditional 

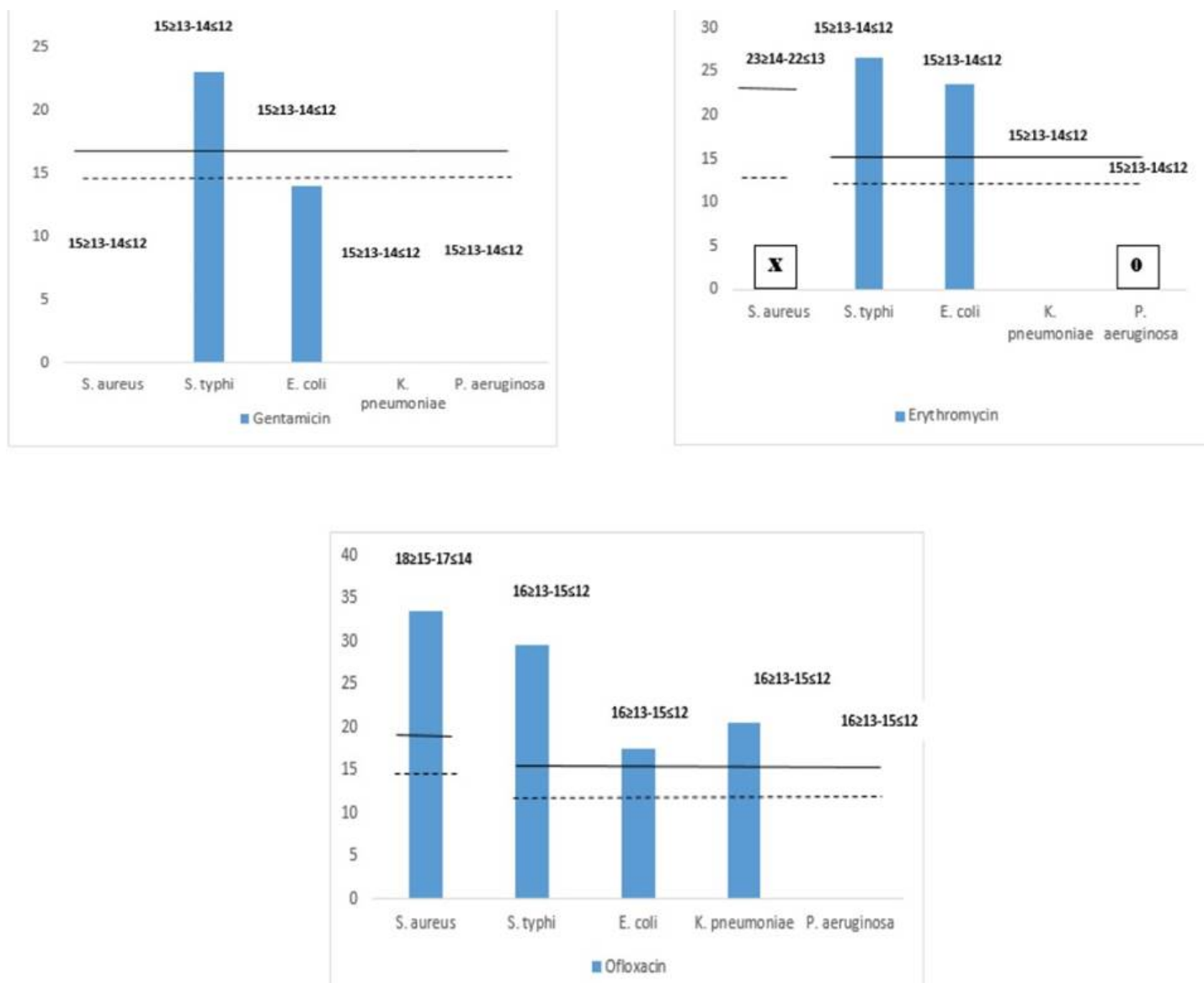

Fig. 5. Antimicrobial activity of some selected antibiotic disc on the tested organisms

and biomedicine healthcare systems is the limitless capability of the plant to produce a large number of these organic compounds of high structural diversity. The accumulation of these bioactive organic compounds in large proportions in plant cells had, over the last 5 decades attracted the attention of academic community, and the knowledge so generated had helped in the inclusion of herbal medicines as a vital component of the healthcare systems, as well as identification of native medicinal plants in indigenous pharmacopeias (Adebolu and Oladimeji, 2005).

The problems experienced in the case management of common infections coupled with increase in mortality/ fatality rate of infections have all been linked to antimicrobial resistance. This increase in antimicrobial resistance especially among bacteria is currently one of the highest global public health threats (CDCP, 2014).

The MIC of the leaf extracts ranged from $5-150 \mathrm{mg} \mathrm{ml}^{-1}$ in the methanolic extract and $5 \mathrm{mg} / \mathrm{ml}$ in ethanolic extract. The effect of the leaf extracts correlates with the reports that microorganisms vary widely in their degree of susceptibility to antimicrobial agents (Anibijuwon et al., 2010). High MIC values are indication of low activity while low MIC values are indication of high activity. In this study, the methanolic extract had higher MIC values for Staphylococcus aureus and Salmonella typhi $150 \mathrm{mg} \mathrm{m}^{-1}$ and $75 \mathrm{mg} \mathrm{ml}^{-1}$ respectively, thus indicating lower susceptibility to the efficacy of the extract. Lower MIC value of $5 \mathrm{mg} \mathrm{ml}^{-1}$ was obtained in the methanolic extract against Pseudomonas aeruginosa, thus indicating higher activity of the extract against the organism. In Salmonella typhi, the MIC was obtained as $150 \mathrm{mg} \mathrm{ml}^{-1}$, this means that lower concentrations other than this concentration cannot exert any antimicrobial effect on the organism (Table 3). No concentration showed inhibition against $E$. coli both in the methanolic and ethanolic extracts except for the stock concentration which was $200 \mathrm{mg} \mathrm{ml}^{-1}$, this simply means that lower concentrations cannot exert antimicrobial activity on the organism. In the ethanolic extract, lower MIC value of $5 \mathrm{mg} \mathrm{ml}^{-1}$ was observed in the organisms $(P$. aeruginosa, $S$. typhi and $S$. aureus), indicating that antimicrobial activity can be exerted by the extract even at lower concentrations (Table 3). No inhibitory activity was observed both in the methanolic and ethanolic extracts against $K$. pneumoniae, and this was speculated that the organism is resistant to the phytochemicals present in the leaf extracts.

The extensive resistance to different classes of antibiotics in this research especially cephalosporins and beta-lactam may suggest the presence of resistance enzymes with inactivating properties in these organisms. Resistance to Penicillins and $\beta$-lactams has been on the increase over the years (Mortensen et al., 2016; Yoon et al., 2017). Some gram negative bacteria have been studied to produce intrinsic chromosomal encoded enzymes that facilitates resistance to Penicillins and beta-lactams (Lee et al., 2011; Matsumura et al., 2015). It was observed that the $\mathrm{pH}$ of the extracts was highly acidic with the ethanol extract being the most acidic. This may support its significant activity on the 
32

bacteria especially Pseudomonas aeruginosa. Generally, bacteria grow better in slightly acidic to slightly alkaline (68.5) medium, and specifically Pseudomonas aeruginosa attains optimum growth at a $\mathrm{pH}$ of 7.5 (Charyulu and Gnanamani, 2010). Previous researches on the evaluation of plants have affirmed that ethanol is a very potent solvent for the extraction of phytochemicals. This could be attributed to its polarity which allows for effective dissolution of the bioactive compounds in it (Anibijuwon et al., 2009).

The aqueous extract was completely non-reactive to any of the test organisms. There could however be a probable reactiveness at higher concentrations. At the stock concentration $\left(200 \mathrm{mg} \mathrm{ml}^{-1}\right)$, Salmonella typhi, Staphylococcus aureus and Escherichia coli were susceptible to both or one of ethanol and methanoic extracts.

\section{Conclusions}

In the traditional setting, water is the widely used solvent used to prepare concoction. The higher activity demonstrated by organic solvents (methanol and ethanol) in the present work is therefore an indication that less of the bioactive principles are extracted when water is used as a solvent. The study has also confirmed that the methanolic and ethanolic extracts of Senna alata possessed reasonable activity against some bacteria and if adjusted to suitable conditions of temperature and $\mathrm{pH}$ and further purified can be utilized for its therapeutic activities in the management of urinary tract and gastrointestinal tract disorders, whereas the infections are caused by underlying causative susceptible bacteria. There is however a need for more research on the activity of the extracts in this plant against a wider range of bacteria and fungi, as well as on the toxicological effects and further purification of the extracts for isolation of the pure active constituents.

\section{References}

Adebolu TT, Oladimeji SA (2005). Antimicrobial activity of leaf extracts of Ocimum gratissmum on selected diarrhea causing bacteria in Southwestern Nigeria. African Journal of Biotechnology 4(7):682-684.

Afrin M (2015). Phytochemical and biological investigation of Senna alata leaves. Doctoral dissertation, East West University.

Anibijuwon II, Udeze AO (2009). Antimicrobial activity of Carica papaya (Pawpaw Leaf) on some pathogenic organisms of clinical origin from South-Western Nigeria. Ethnobotanical Leaflets 7:4.

Centers for Disease Control and Prevention. Antibiotic Resistance Threats in the United States (CDCP) (2014). Retrieved 2017 Nov 12 from http://www.cdc.gov/drugresistance/threat-report-2014/pdf/ar-threats2013-508.pdf.

Charyulu EM, Gnanamani A (2010). Condition stabilization for Pseudomonas aeruginosa MTCC 5210 to yield high titers of extra cellular antimicrobial secondary metabolite using response surface methodology. Current Research in Bacteriology 4:197-213.
Cheesbrough M (2006). District laboratory practice in tropical countries. Cambridge University Press.

Clinical and Laboratory Standards Institute (CLSI) (2016). Performance standards for antimicrobial susceptibility testing; Twenty-sixth informational supplement. CLSI document M100-S26. Wayne, PA: Clinical and Laboratory Standards Institute.

De Cock KM, Simone PM, Davison V, Slutsker L (2013). The new global health. Emerging Infectious Diseases 19(8):1192-1197.

Ekor M (2013). The growing use of herbal medicines: issues relating to adverse reactions and challenges in monitoring safety. Frontiers in Pharmacology 4:177.

Hubert J, Mabagala R, Mamiro D (2015). Efficacy of selected plant extracts against Pyricularia grisea, causal agent of rice blast disease. American Journal of PlantSciences 17:602-611.

Katiyar C, Gupta A, Kanjilal S, Katiyar S (2012). Drug discovery from plant sources: An integrated approach. AYU 33(1):10.

Lee N, Huang W, Tsui K, Hsueh P, Ko W (2011). Carbapenem therapy for bacteremia due to extended-spectrum $\beta$-lactamase-producing Escherichia coli or Klebsiella pneumoniae. Diagnostic Microbiology and Infectious Disease 70(1):150-153.

Mahmood AM, Amey JM (2007). In vitro antibacterial activity of Parkia biglobosa (Jacq) root, bark extract against some microorganisms associated with urinary tract infections. African Journal of Pharmacology 6(11):1272-1275.

Matsumura N, Iyobe SH, Kusadokoro J, Ozaki S Minami, S Haruta, T Sawai, KO'Hara (2000). Amino acid substitutions in a variant of IMP1 metallo- $\beta$-lactamase. Antimicrobial Agents Chemotherapy $44(8): 2023-2027$

Mortensen L, Kristiansen, BE Sandnes RA (2016).The prevalence of antibiotic resistance in bacterial respiratory pathogens from Norway is low. Clinical Microbiology and Infection 7(12):682-687.

Saikat Sen, Raja Chakraborty (2016). Revival, modernization and integration of Indian traditional herbal medicine in clinical practice: Importance, challenges and future. Journal of Traditional and Complementary Medicine 7(2):233-234.

Trease GE, Evans WC (1978). Pharmocology,11th ed. Bailliere Tindall Ltd, London pp 60-75.

Willey JM, Sherwood LM, Woolverton CJ (2008). Prescott, Harley and Kleins Microbiology, 7th ed. McGraw Hill Company New York. America.

Yoon Ki-Bok, Byung-Joon Song, Mi-Yeong Shin, Hyun-Cheol Lim, YeonHee Yoon, Doo-Young Jeon, Hoon Ha, Soo-In Yang, Jung-Beom Kim (2017). Antibiotic resistance patterns and serotypes of Salmonella spp. isolated at Jeollanam-do in Korea. Osong Public Health and Research Perspectives 8(3):211-219. 